\title{
Experimental Investigation of Reactive-Inert Particulate Matter Detachment from Metal Fibres at Low Flow Velocities and Different Gas Temperatures
}

\author{
Julian Zoller ${ }^{1}$ - Amin Zargaran ${ }^{2} \cdot$ Kamil Braschke $^{2} \cdot$ Jörg Meyer $^{1} \cdot$ Uwe Janoske $^{2} \cdot$ Achim Dittler $^{1}$
}

Received: 22 June 2020 / Revised: 22 October 2020 / Accepted: 26 October 2020 / Published online: 11 November 2020

(c) The Author(s) 2020

\begin{abstract}
The detachment of particle structures from single fibres in gas flow has been investigated only for inert particle structures yet. This study investigates the detachment of particle structures containing reactive components. These reactive components disappear during the reaction and enhance detachment at low flow velocities. Soot was used as the reactive component and glass spheres as the inert component of the particle structure. The soot disappears due to combustion with oxygen leaving only the glass spheres on the fibre. Without reaction, the detachment phenomenon was observed at superficial flow velocities above $1.9 \mathrm{~m} / \mathrm{s}$ and with reaction at $0.5 \mathrm{~m} / \mathrm{s}$. This shows that reacting and disappearing components of the particle structure can enhance detachment.
\end{abstract}

Keywords Detachment $\cdot$ Reaction $\cdot$ Fibre $\cdot$ Particle structure $\cdot$ Re-entrainment

\section{Introduction}

Electronic supplementary material The online version of this article (https://doi.org/10.1007/s41810-020-00081-3) contains supplementary material, which is available to authorized users.

Julian Zoller

julian.zoller@kit.edu; gps@mvm.kit.edu

Amin Zargaran

zargaran@uni-wuppertal.de

Kamil Braschke

braschke@uni-wuppertal.de

Jörg Meyer

joerg.meyer@kit.edu

Uwe Janoske

janoske@uni-wuppertal.de

Achim Dittler

achim.dittler@kit.edu

1 Institute of Mechanical Process Engineering and Mechanics, Karlsruhe Institute of Technology, Straße am Forum 8, 76131 Karlsruhe, Germany

2 School of Mechanical Engineering and Safety Engineering, Chair of Fluid Mechanics, Bergische Universität Wuppertal, Gaußstraße 20, 42119 Wuppertal, Germany

The detachment of particles and particle structures from a single filter fibre was first investigated by Löffler. Löffler showed that gas flow velocities above $10 \mathrm{~m} / \mathrm{s}$ are necessary to detach more than $50 \%$ of single $10-\mu \mathrm{m}$ glass spheres from a single polyamide fibre of $50-\mu \mathrm{m}$ diameter. An increasing flow velocity during particle deposition on the fibre and fixed primary particle layers both increase the velocity, necessary for detachment. For piles of particles, first detachment phenomena were observed at $1.2 \mathrm{~m} / \mathrm{s}$. (Löffler 1972).

Following Löffler, only few researchers investigated the detachment of particles from fibres, because common flow velocities in fibrous filters are below the velocities necessary for detachment. The reason for the lower flow velocities in filter applications is the reduction of particle bounce (Maus et al. 1996), and hence an increase in particle deposition efficiency (Rembor et al. 1999). These researchers mainly investigated applications, in which even the detachment of small amounts of particles is of relevance.

Qian et al. (1997) studied the release of pathogens from respirators. He observed the first detachment phenomena of $1-5-\mu \mathrm{m}$ polystyrene latex beads at $0.7 \mathrm{~m} / \mathrm{s}$. It was shown that detachment does not depend on how fast the final detachment velocity is reached (Qian et al. 1997). 
Jankowska et al. (2000) observed less than 1\% detachment of fungal spores and of $2.55-\mu \mathrm{m}$ and $3.25-\mu \mathrm{m} \mathrm{KCl}$ particles at $0.09 \mathrm{~m} / \mathrm{s}$ from filter media.

Detachment during filtration was considered in the simulations of Przekop et al. (2004). The authors calculated $10-20 \%$ lower deposition efficiencies of $0.01-10-\mu \mathrm{m}$ particles on single fibres at $0.1 \mathrm{~m} / \mathrm{s}$ if detachment was regarded.

This literature overview shows that only few research projects were done on particle detachment from single fibres, because the necessary flow velocities are rather high compared with common filtration conditions. None of these research projects considered the weakening of particle structures due to reaction and disappearance of reactive components mixed with inert components, which may cause detachment even at low flow velocities.

In this study, the influence of reacting and disappearing components on particle structure detachment from single filter fibres and fibrous filters is investigated. The particle structure investigated in this study consists of soot, which disappears during reaction/combustion, and glass spheres, which do not react under the given conditions. Steel wool and single steel fibres are used as the particle collector. Steel wool is used to demonstrate that detachment during the reaction can occur in filter media, but further investigations are performed with single steel fibres because of the better optical accessibility and the better-known conditions. The detachment experiments with single fibres are made with reaction/ with air at high temperatures and without reaction/ with air at ambient temperatures to show the influence of reaction on detachment. Experiments with nitrogen at high temperatures are also performed to evaluate the influence of temperature on detachment without reaction. Theoretical considerations are made to gain further insight into causes of the detachment phenomena.

\section{Materials and Methods}

\subsection{Experimental Setup and Procedure}

The reactive-inert particle structures, the detachment of which is investigated in this study, are built by filtration of an aerosol containing soot (reactive component) and glass spheres (inert component) with steel wool $(40-\mu \mathrm{m}$ fibre diameter) or single steel fibres (40- $\mu \mathrm{m}$ fibre diameter) as the collector. Figure 1 shows the experimental setup used to build the particle structures.

The soot is produced with a soot generator (miniCast $6204 \mathrm{C}$, manufacturer Jing Ltd) by quenching of a propane flame. The soot generator was operated with $50 \mathrm{ml}_{\mathrm{N}} / \mathrm{min}$ propane, $0 \mathrm{ml}_{\mathrm{N}} / \mathrm{min}$ mixing nitrogen, $11_{\mathrm{N}} / \mathrm{min}$ oxidation air, $01_{\mathrm{N}} /$ min dilution air and $21_{\mathrm{N}} /$ min quench nitrogen. The particle size distribution of the produced soot is shown

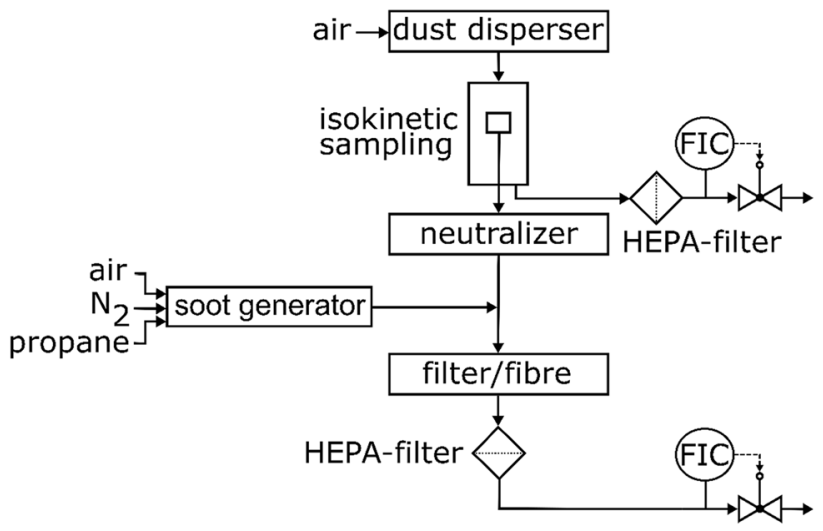

Fig. 1 Schematic setup to produce an aerosol containing soot and glass spheres and deposit it on a filter or single fibres. The schematic diagram is not true to scale

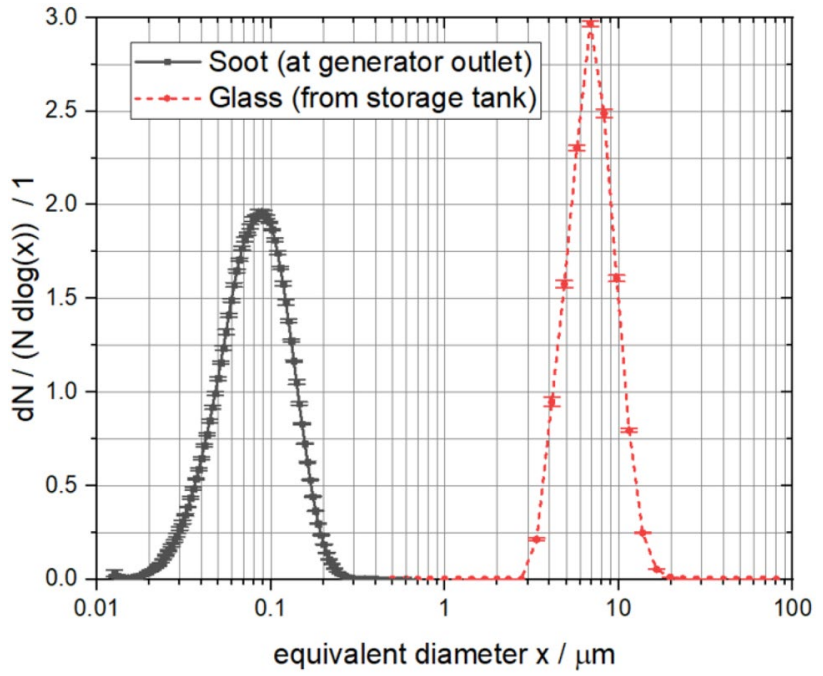

Fig. 2 Particle size distributions of soot at the outlet of the soot generator and glass spheres inside the storage tank of the dust disperser. Error bars denote the standard deviation

in Fig. 2. The size distribution was measured at the generator outlet after immediate dilution with $200 \mathrm{l} / \mathrm{min}$ air using a scanning mobility particle sizer (3756 UCPC, 3082 classifier unit, 3081 DMA, manufacturer TSI GmbH). In this chart, $N$ denotes the number of particles; and $x$, their equivalent diameter. The soot-aerosol flows directly to the filter/fibre without further processing. A fraction of 5000 CP00 Spheriglass glass spheres (manufacturer Potters industries LLC) is used as the inert component. Figure 2 also shows the particle size distribution of the glass spheres, which were filled into the dust disperser. The size distribution was measured using laser diffraction (Helos, manufacturer Sympatec $\mathrm{GmbH}$ ) at a propellant pressure of 1.5 barg (barg denotes overpressure). 
Table 1 Particle deposition conditions at the filter/fibre

\begin{tabular}{lll}
\hline Collector & Steel wool & Steel fibre \\
\hline Soot concentration $/\left(\mathrm{mg} / \mathrm{m}^{3}\right)$ & $150 \pm 17$ & $150 \pm 17$ \\
Glass concentration $/\left(\mathrm{mg} / \mathrm{m}^{3}\right)$ & $109 \pm 54$ & $109 \pm 54$ \\
Superficial flow velocity $/(\mathrm{m} / \mathrm{s})$ & 1.5 & 0.9 \\
Fibre diameter $/(\mu \mathrm{m})$ & 40 & 40 \\
Time $/ \mathrm{min}$ & 60 & 120 \\
\hline
\end{tabular}
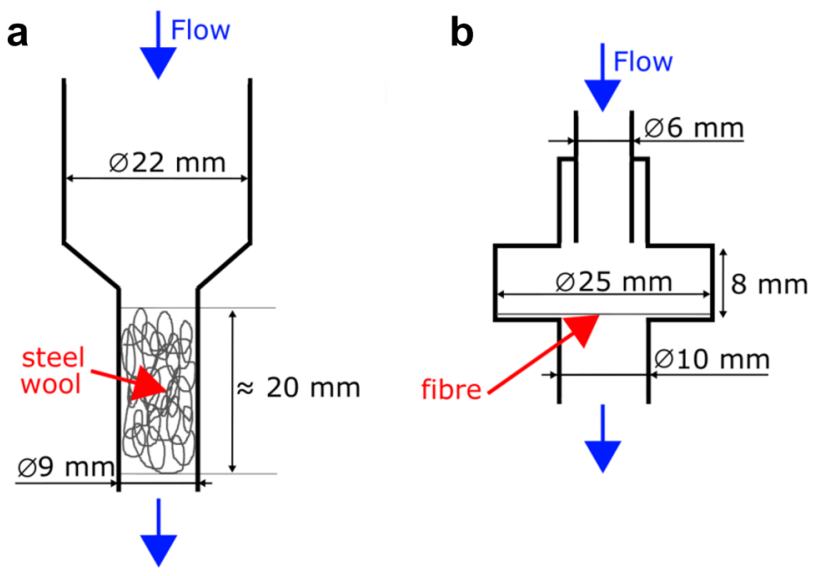

Fig. 3 Schematic diagrams of $\mathbf{a}$ filter and $\mathbf{b}$ fibre holder for particle deposition

The glass spheres are dosed by a rotating ring and dispersed by an ejector (SAG 410U, manufacturer Topas $\mathrm{GmbH})$. The dust disperser worked at a preparation rate of $67 \%$, a ring rotation rate of $10 \%$ and an air pressure upstream the disperser of about $1.5 \mathrm{barg}$. An isokinetic sampling apparatus divided the glass sphere mass flow to attain a low mass flow rate of about $26 \mathrm{mg} / \mathrm{h}$ at the filter/fibre. The isokinetic sampling apparatus consists of a pipe with an inner diameter of $50 \mathrm{~mm}$ and a cylindrical probe head with a diameter of $12 \mathrm{~mm}$ positioned coaxially in the pipe (see Fig. 1). A Kr-85 neutraliser was placed downstream the isokinetic sampling to reduce the electrical charge of the glass spheres. This is necessary because glass spheres, dispersed by an ejector, have a higher electrical charge than soot, produced by the combustion, according to the literature (Johnston et al. 1987; Onischuk et al. 2003). This different charge would affect particle deposition and adhesion on the filter/fibre and was, therefore, reduced using a neutraliser. The deposition conditions at the filter/fibre are summarised in Table 1.

A sketch of the filter and fibre holder used for particle deposition is shown in Fig. 3. The steel wool was put inside the reduction piece of a glass tube and the fibre was fixed at the centring ring of an ISO-KF seal (manufacturer Pfeiffer Vacuum Components \& Solutions $\mathrm{GmbH}$ ). A quarter of the centring ring is sawed off for better optical accessibility during the detachment experiments.

The loaded filter/fibre was mounted below a macroscope (Wild M3C, manufacturer Leica Camera AG) in a way that allowed detachment experiments with hot air from a tube furnace (MTF 12/25/400, manufacturer Carbolite Gero $\mathrm{GmbH} \& \mathrm{Co} . \mathrm{KG})$. An USB camera was used to capture video material of the detachment process. The setup is shown in Fig. 4a for the filter and $b$ for the fibre.

The obtained video material of the single fibres was analysed according to the procedure shown in Fig. 5. This procedure was implemented using MATLAB ${ }^{\odot}$ and calculated the projection area of fibre and deposits for each

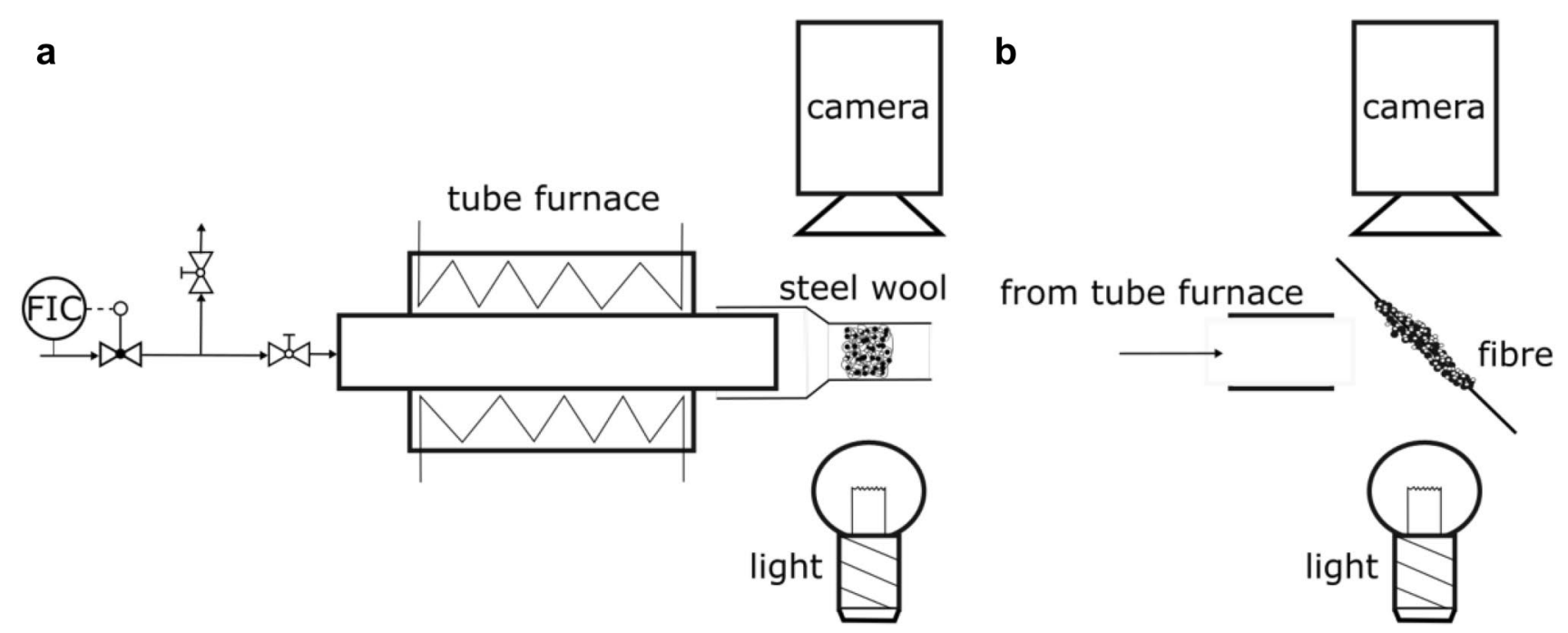

Fig. 4 Schematic setup for investigation of detachment of reactive-inert particle structures from a steel wool or b single fibres. The schematic diagram is not true to scale 


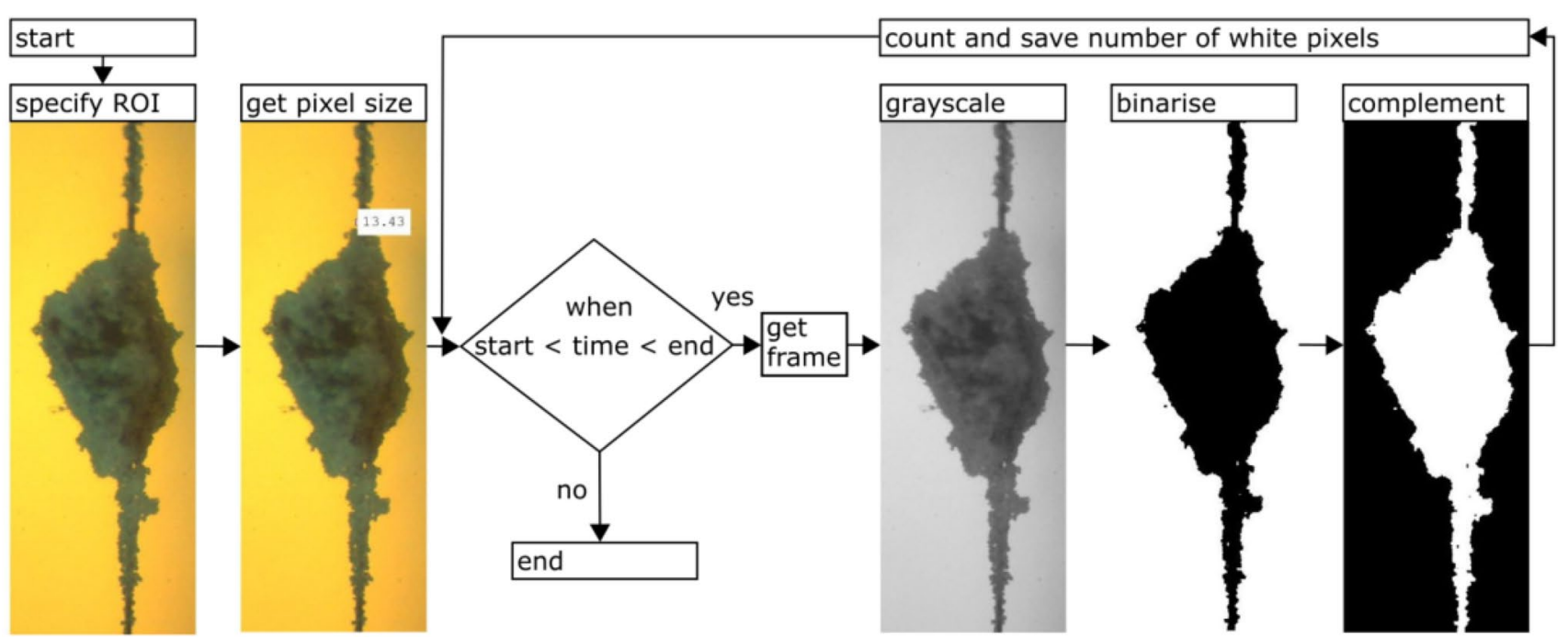

Fig. 5 Procedure for image analysis of the recorded data

timestamp of the experiment. The projection area is a measure for the fibre load but can also be used to determine the size of the detached particulate structures.

The first step in the image analysis procedure is the specification of the region of interest (ROI). The ROI should be as small as possible to minimise the effect of background noise on the analysis. Then the size of a single pixel in the picture is determined by counting the pixels of the bare fibre diameter. The fibre diameter is $40 \mu \mathrm{m}$ and so the size of a pixel could be calculated. After that, a loop over all frames in a certain time range counts the pixels of the projection area over the time. In this loop the current frame is first converted into grayscale. The grayscale picture is binarised using the method of Otsu (1979), which is often used in image analysis to calculate the optimal threshold for each frame. The binarised image is inverted, and the number of white pixels, which represents the projection area of fibre and deposit, is counted.

Rotation and shifts of the fibre and particle structures, as well as streaks occurring during the experiments with temperature cause significant measurement errors. Streaks for example cause fluctuations in the projection area, which are equivalent to the detachment and deposition of particles with a diameter of $250 \mu \mathrm{m}$. The detachment of particulate structures is, therefore, not automatically detected and the equivalent diameter of the detached particulate structures is calculated by averaging the projection area of fibre and particle structure immediately before and after detachment. The measurement error of the calculated equivalent diameter can be estimated by calculating the maximum and minimum equivalent diameter if the maximum and minimum projection areas immediately before and after detachment are used for determination of the projection area of the detached particle structure.

Additional experimental errors are caused by inhomogeneities of the flow and the temperature profile along the fibre.

\subsection{Theoretical Considerations}

The experiments (Sect. 3.1) show that different velocities are necessary to detach components of particle structures from single filter fibres with and without reaction of soot. Because the reaction mainly affects the particle structure itself, it is supposed that changes in the adhesion force and breaking stress of the structure cause the different detachment velocities. This section provides common and simple equations to calculate the breaking stress of particle structures, to evaluate which particle structure parameter changes, have the highest influence on the breaking stress and hence most likely on the necessary detachment velocity.

The theoretical breaking stress $\sigma_{\mathrm{th}}$ of a particle structure can be calculated according to Rumpf (1970):

$\sigma_{\text {th }}=\frac{1-\varepsilon}{\varepsilon} \frac{F_{\text {adh }}}{x^{2}}$,

where $\varepsilon$ denotes the porosity of the structure; $F_{\text {adh,corr }}$, the mean and corrected adhesion force between the particles in the structure; and $x$, the particle diameter.

As adhesion forces $F_{\text {adh }}$, only van der Waals forces are regarded. Liquid bridges also occur but are not able to explain experimental results, as shown later by experiments at high temperatures with and without reaction. 
The adhesion force for hard materials can be calculated according to Hamaker (1937).

$F_{\text {adh }}=\frac{A_{i, j}}{24} \cdot \frac{x}{a^{2}}$.

In this equation, $A_{i, j}$ denotes the Hamaker constant between material $i$ and $j$; and $a$, the contact distance.

Using Eqs. 1 and 2, the breaking stress ratio of the particle structures before (index: bef) and after (index: aft) reaction can be written as:

$\frac{\sigma_{\text {th,bef }}}{\sigma_{\text {th,aft }}} \sim \frac{\left(1-\varepsilon_{\text {bef }}\right) \cdot \varepsilon_{\text {aft }}}{\varepsilon_{\text {bef }} \cdot\left(1-\varepsilon_{\text {aft }}\right)} \cdot \frac{x_{\text {aft }}}{x_{\text {bef }}} \cdot \frac{A_{i, j, \text { bef }}}{A_{i, j, \mathrm{aft}}} \cdot \frac{a_{\text {aft }}^{2}}{a_{\text {bef }}^{2}}$.

The factors on the right-hand side of Eq. 3 can be used to evaluate the influence of different particle structure parameters on the change of the structures breaking stress during reaction.

Equation 3 only regards van der Waals forces. The adhesion forces in the experiments are also influenced by temperature effects and liquid bridges, as discussed in Sect. 3.1.

\section{Results and Discussion}

\subsection{Experimental Results}

The detachment of agglomerates from steel wool is shown in Fig. 6. The particle structure was build at the conditions mentioned in Table 1 with a flow direction from right to left. The temperature was measured at the outlet of the glass tube; therefore, the real temperature inside the filter is assumed to be higher, as it is closer to the tube furnace. The pictures show the filter $10 \mathrm{~mm}$ downstream the filter surface. The figure shows, a detachment, which occurs under this operating conditions (red circle), but the majority of particle structures adhere to the fibres. The changing colour of the particle structures indicate the oxidation of soot. The fibres move slightly during operation, which causes the shift of the later detaching particle structure from the picture at $0 \mathrm{~s}$ to the picture at $329 \mathrm{~s}$.

Although the superficial velocity (average velocity over the tube cross section) is constant until the first particle structure detaches, detachment occurs not with the start of the flow but after a rather long time of $6 \mathrm{~min}$ and $29 \mathrm{~s}$. This
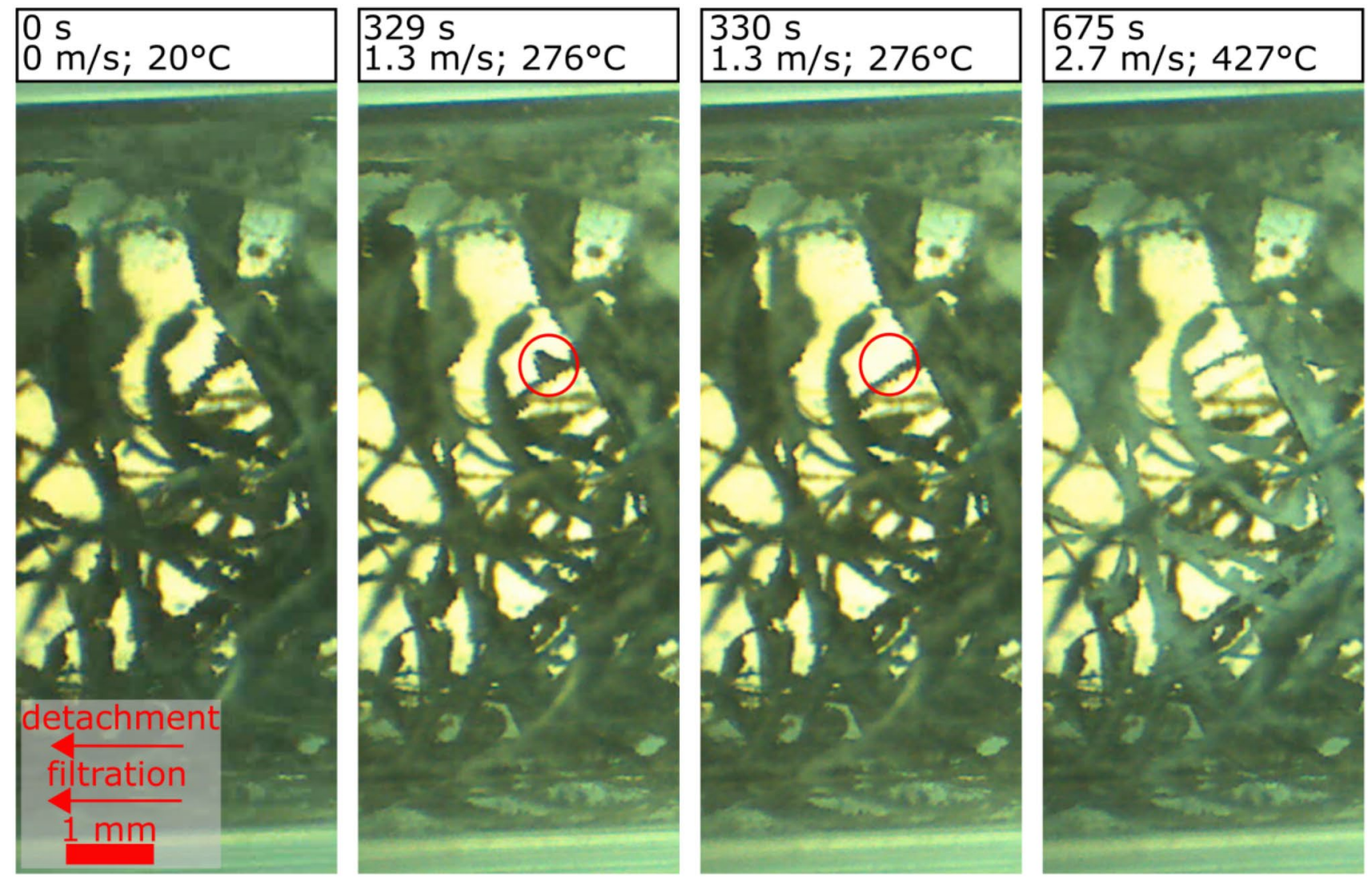

Fig. 6 Local detachment of particle structures consisting of soot and glass spheres in a steel wool filter. Particle structures were built at the conditions summarised in Table 1 
indicates that the reaction of soot may play a role during the detachment of the particle structure because the soot oxidation also needs a long time. Nevertheless, most particle structures adhere to the fibres, indicating that the detachment is rather rare.

The interpretation of experiments with steel wool is difficult, because the flow and temperature conditions inside the filter can only be estimated and repeatable filter packing is hard to achieve. Therefore, three types of experiments with single steel fibres were made. First, the velocity necessary for detachment of soot-glass particle structures was measured without reaction/ with air at ambient temperature, then the same velocity was measured with reaction/ with air at elevated temperature. To evaluate the role of volatile or fluid components in the particle structure, experiments without reaction at elevated temperature/ with nitrogen at elevated temperature were performed too.

The particle structures build on the fibres at the conditions mentioned in Table 1 had an average ratio of projection area to fibre length of $0.76 \mathrm{~mm}$ with an empirical standard deviation of $0.48 \mathrm{~mm}$.

Figure 7 shows one of the detachment experiments of such a particle structure without reaction and Fig. 8 one with reaction. The flow direction during particle deposition due to filtration and during particle structure detachment opposes each other and are indicated by the arrows in the picture. The reason for the different flow direction is that backflushing is a common procedure in filtration and the authors suppose that the opposing flow direction during detachment enhance the detachment of agglomerates. The red circles in the figures show particle structures which detach in the experiment. The figures show that detachment without reaction occurs at a superficial velocity above $1.9 \mathrm{~m} / \mathrm{s}$ and with reaction at $0.5 \mathrm{~m} / \mathrm{s}$ after most of the visible soot is burned.

In both experiments, only small amounts of the particle structure detach from the fibre and detachment occurred not in every repetition of this type of experiment. It is, therefore, necessary to further quantify the observed detachment phenomena in relation to the fibre length or the total projection area of the particle structure. Table 2 shows three approaches for this quantification. The detached projection area is the sum of the detached particle structures projection areas, which were predicted by calculating the projection area over time with the procedure mentioned in Fig. 5 and subtraction of the entire projection area before and after a detachment incident. The detached projection area is compared to the total projection area, which is the sum of all projection areas at the start of the experiment.

These results show that no detachment occurs at superficial flow velocities below $1.9 \mathrm{~m} / \mathrm{s}$ if no reaction takes place.
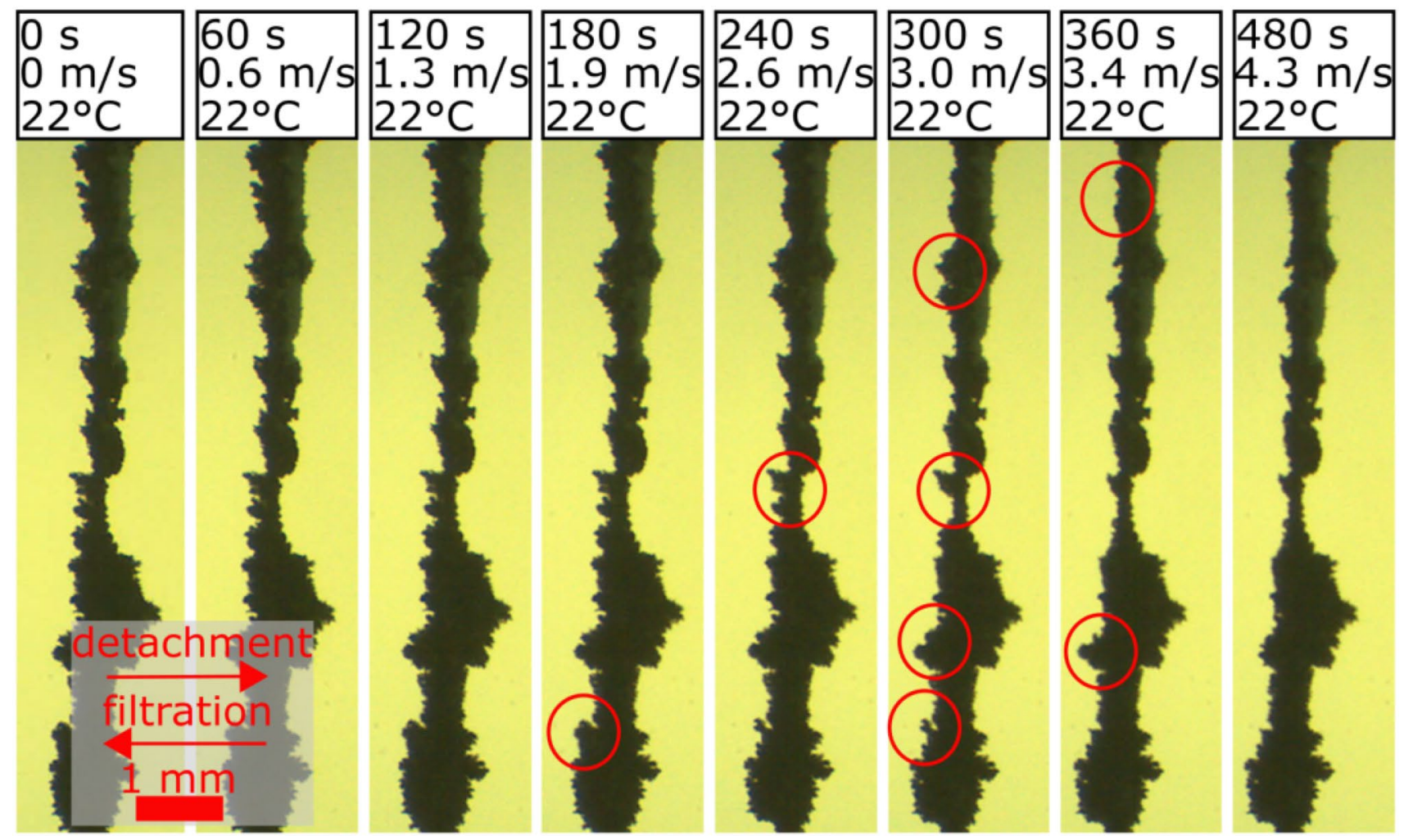

Fig. 7 Local detachment of particle structures consisting of soot and glass spheres without reaction/ with air at ambient temperature. Particle structures were built at the conditions summarised in Table 1 

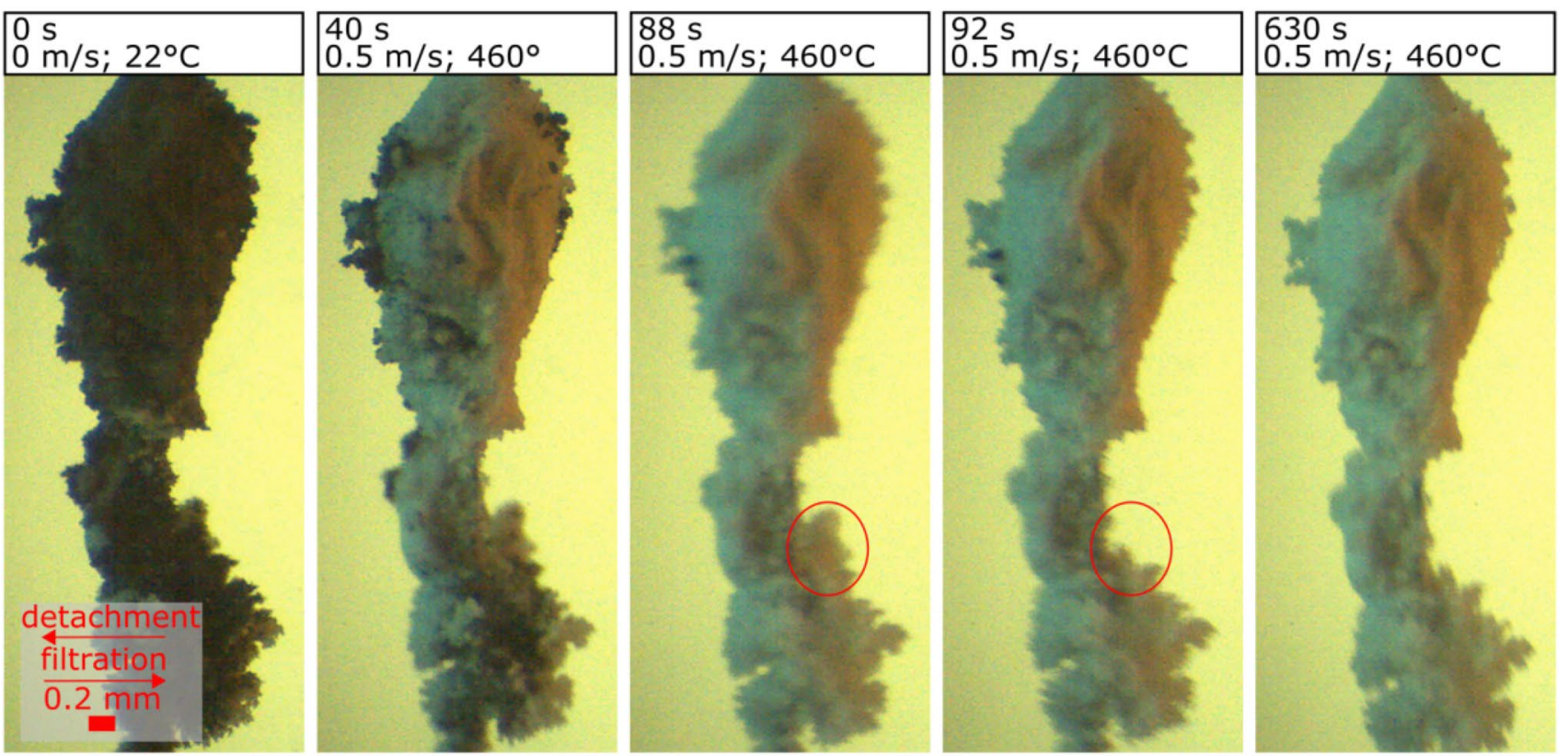

Fig. 8 Local detachment of particle structures consisting of soot and glass spheres with reaction. Particle structures were built at the conditions summarised in Table 1

Table 2 Results of detachment experiments with and without reaction.

\begin{tabular}{|c|c|c|c|c|}
\hline & $\begin{array}{l}\text { No reaction } \\
<1.9 \mathrm{~m} / \mathrm{s}<25^{\circ} \mathrm{C}\end{array}$ & $\begin{array}{l}\text { No reaction } \\
<2.6 \mathrm{~m} / \mathrm{s}<25^{\circ} \mathrm{C}\end{array}$ & $\begin{array}{l}\text { Reac- } \\
\text { tion }<0.5 \mathrm{~m} / \mathrm{s}>350{ }^{\circ} \mathrm{C}\end{array}$ & $\begin{array}{l}\text { Reaction } \\
0.5 \mathrm{~m} / \mathrm{s}>400{ }^{\circ} \mathrm{C}\end{array}$ \\
\hline Detached structures per no. of experiments/(1) & $0 / 6$ & $3 / 6$ & $0 / 10$ & $3 / 6$ \\
\hline Detached structures per fibre length/ $\left(\mathrm{cm}^{-1}\right)$ & $0.0 / 1$ & $0.84 / 1$ & $0.0 / 1$ & $1.44 / 1$ \\
\hline $\begin{array}{l}\text { Detached projection area per total projection area/ } \\
\left(\mathrm{mm}^{2} / \mathrm{mm}^{2}\right)\end{array}$ & $0.0 / 16.92$ & $0.05 / 16.92$ & $0.0 / 43.52$ & $0.56 / 16.21$ \\
\hline
\end{tabular}

The particle structures were built at the conditions in Table 1

In case of reaction, detachment is possible even at lower superficial flow velocities of $0.5 \mathrm{~m} / \mathrm{s}$. The number of detachment phenomena per fibre length is about 1 detachment per $1 \mathrm{~cm}$ of fibre length in the case of reaction at $0.5 \mathrm{~m} / \mathrm{s}$ or in the case without reaction at $1.9-2.6 \mathrm{~m} / \mathrm{s}$. The projection area of the detached particle structures is smaller than $3.5 \%$ of the projection area of the whole particle deposits, which shows that the majority of the particle structure adheres to the fibre under the investigated conditions.

Figure 9 depicts two particle structures one before and one after reaction with a scanning electron microscope. The particle structures were built under the conditions in Table 1 and reaction occurred at $0.5 \mathrm{~m} / \mathrm{s}$ and $474{ }^{\circ} \mathrm{C}$ in air. The pictures show that the soot between the glass spheres oxidises almost completely. The picture on the top right also shows that the soot is inhomogeneously distributed between the glass spheres. This may explain, why only parts of the particle structure detach during reaction, because local particle structures may differ significantly in a way that supports or hinders detachment.

Besides the reaction of a part of the particle structure, also the evaporation of volatile components could enhance detachment. Volatile components are water and volatile organic compounds (VOC), which are both produced during the combustion in the soot generator. These volatiles could build capillary bridges between particles and therefore increase the velocity necessary for detachment. Increased temperatures may evaporate these volatiles and therefore decrease the velocity necessary for detachment. To distinguish between the detachment enhancement caused by the reaction of soot and the evaporation of volatiles, detachment experiments were made with nitrogen at increased temperature.

Four fibres were loaded according to the conditions in Table 1. Detachment experiments were performed with nitrogen at temperatures above $100{ }^{\circ} \mathrm{C}$ and below $500{ }^{\circ} \mathrm{C}$ to 

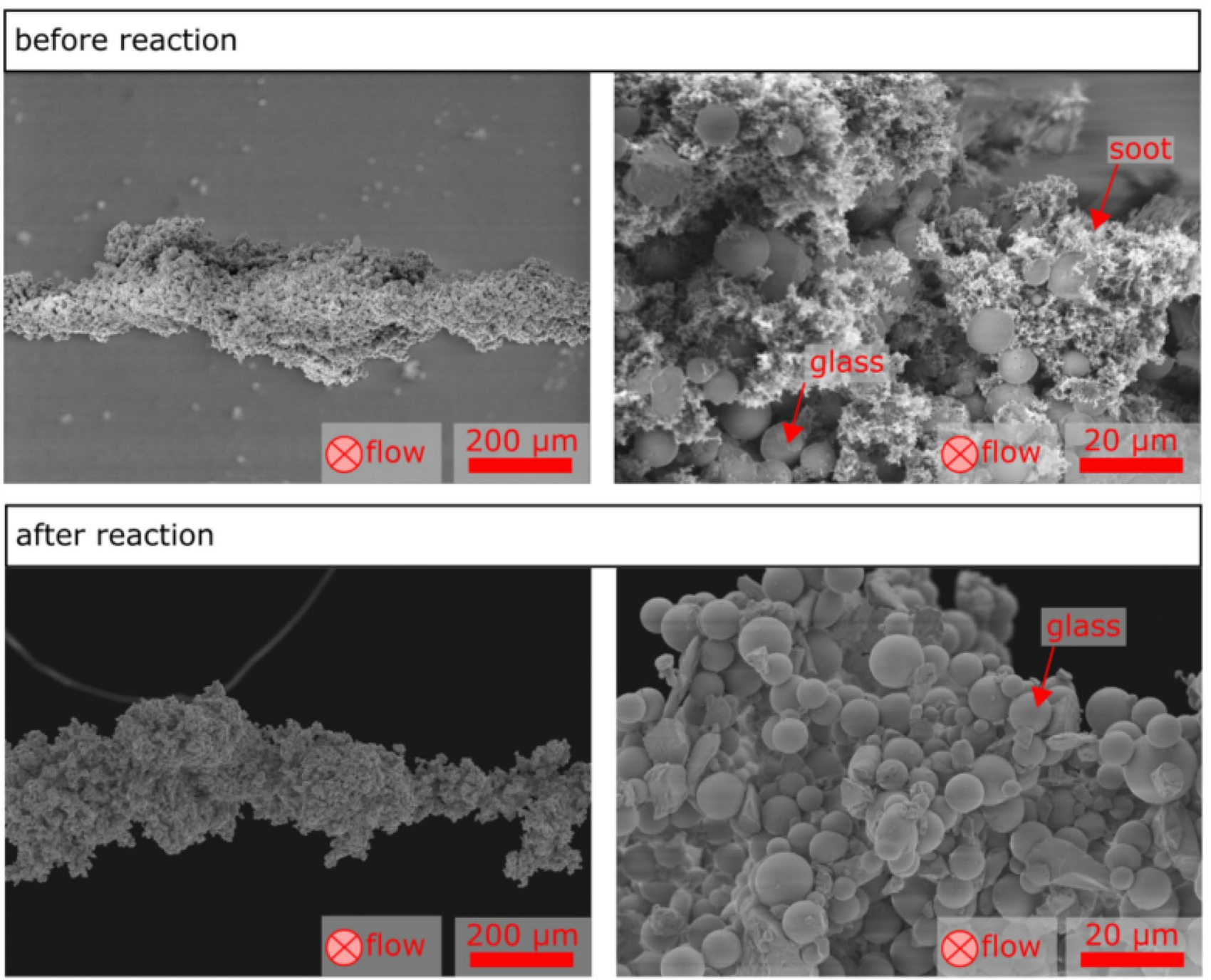

Fig. 9 Pictures of a particle structures before and after reaction made with a scanning electron microscope. Particle structures were built at the conditions summarised in Table 1 . Reaction occurred at $0.5 \mathrm{~m} / \mathrm{s}$ and $474{ }^{\circ} \mathrm{C}$. Pictures show the windward side of the fibre

evaporate water but not too high to sinter the glass spheres together. Figure 10 shows one of the four experiments. In all four experiments, detachment could not be observed below $3.0 \mathrm{~m} / \mathrm{s}$. This shows that high temperatures without reaction do not enhance detachment, because detachment occurred at ambient temperature and without reaction at velocities below $3.0 \mathrm{~m} / \mathrm{s}$. The evaporation of capillary water bridges, as observed by Lai et al. for temperatures above $150{ }^{\circ} \mathrm{C}$ (Lai et al. 2015), is, therefore no explanation for the detachment of reacting particle structures from fibres at high temperatures and low flow velocities.

The detachment experiments with nitrogen at higher temperatures show, that higher temperatures increase the velocity necessary for detachment. The reason for this may be increasing adhesion forces due to elastic deformation, plastic deformation, sintering, viscoelastic flattening and surface reactions as reported in literature (Berbner et al. 1994). The Hamaker constants of materials can also increase with temperature, as Jiang et al. showed for copper, gold and silver nanoparticles (Jiang et al. 2016), which can further increase adhesion forces and hence detachment velocities. The temperature dependent formation of capillary bridges made of tar, similar to those made of water observed by Lai et al. (2015), is also possible. Hurley et al. observed an increase in tensile strength of an pressurised fluidised bed combustion carbon dust of $45 \mathrm{~N} / \mathrm{mm}^{2}$ for a temperature rise from 700 to $750{ }^{\circ} \mathrm{C}$ (Hurley et al. 2003), which shows that this phenomena can also occur using real-world particle structures. There are many effects, which can change the adhesion force of particle structures with temperature and different effects may dominate in different temperature regions; therefore, further investigations are necessary to determine the dominating effects in the experiments of this study. 

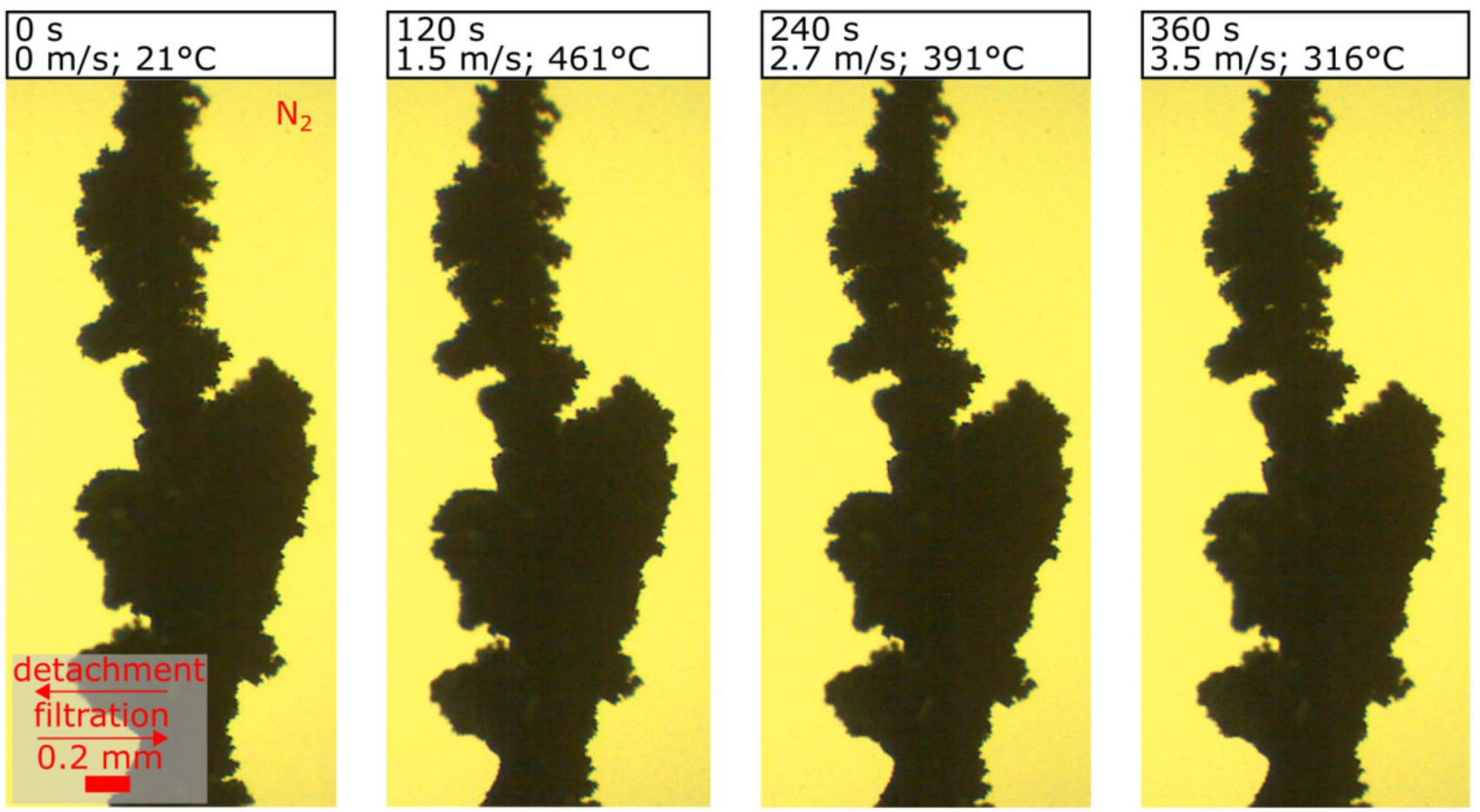

Fig. 10 Detachment experiment of particle structures consisting of soot and glass spheres with nitrogen flow at elevated temperature. No detachment was observed. Particle structures were built at the conditions summarised in Table 1

However, it is remarkable that the velocities necessary for detachment are lower with reaction at higher temperature than without reaction at lower temperature even though the high temperature increases adhesion forces.

\subsection{Theoretical Discussion}

The experiments show an influence of temperature and reaction on the velocity necessary to detach particle structure components. This influence is most likely caused by changes in the particle structure parameters. Equation 3 can be used, to evaluate which parameters contribute most to the change in particle structures breaking stress, and hence detachment velocity.

The porosity before reaction is assumed to be 0.95 , as measured by Kim for a soot filter cake (Kim 2009). After reaction, about half of the former solid fraction vanished, resulting in a porosity of 0.975 . This results in a decrease of the breaking stress by a factor of 2 .

The surface weighed mean diameter of glass particles and soot agglomerates in the structure before reaction is $209 \mathrm{~nm}$. After reaction, the surface weighed mean diameter is $8800 \mathrm{~nm}$, which is the diameter of glass spheres alone. This results in a decrease of the breaking stress by a factor of 42 .

The Hamaker constant before reaction is the average of the Hamaker constants for glass-glass, soot-soot and glass-soot contact (Dahneke 1972) and hence $2.51 \times 10^{-19} \mathrm{~J}$. After reaction, the Hamaker constant is supposed to be the same as for the glass-glass contact alone of $8.53 \times 10^{-20} \mathrm{~J}$ (Dahneke 1972). This results in a decrease of the breaking stress by a factor of 3 .

A contact distance of $0.4 \mathrm{~nm}$ is commonly assumed according to literature (Götzinger et al. 2004), but surface roughness can lead to high deviations in adhesion force calculated with this contact distance. Measured adhesion forces are about a factor between 50 and 175 lower for $8 \mu \mathrm{m}$ glass, polystyrene or tin particles on mica or graphite substrates according to Schaefer et al. (1995), because of the surface roughness. The height coordinate during line scans of glass spheres and soot agglomerates using atomic force microscopy varies about $20 \mathrm{~nm}$ for both materials (Schaefer et al. 1995; Moore et al. 2014) which means that the surface roughness and contact distance before and after reaction may be roughly the same. However, exact contact distances are unknown although they strongly affect the breaking stress of particle structures, as shown by Eq. 3 .

In summary, the surface weighed mean diameter is supposed to be the main contributor for the decrease in breaking stress during reaction. An explanation for the high influence of the surface weighed mean particle diameter on the breaking stress is the increasing number of contact points per particle surface area (or also per particle volume) for decreasing particle diameters. 
This analysis shows that changes in particle structure properties strongly influence the breaking stress of the particle structure and hence its detachment velocity. Inhomogeneous particle structure properties may, therefore, result in local detachment phenomena as observed in the experiment.

The influences of temperature and moisture are neglected in the above theoretical discussion but were already discussed in Sect. 3.1.

The local particle structure properties in the experiments are unknown and only assumed in this analysis. Simulations using computational fluid dynamics are planned, to better understand the influence of local particle structure properties on detachment.

\section{Conclusion}

The influence of reacting and disappearing particle structure components on detachment of particle structures from fibres in gas flow was investigated in this study. The particle structures consist of soot (reactive component) and glass spheres (inert component) deposited by filtration. The main results are:

- Local detachment of particle structures from filters made of steel wool was observed at velocities above $1.3 \mathrm{~m} / \mathrm{s}$ and temperatures above $276^{\circ} \mathrm{C}$. The majority of the particulate deposits remained on the fibres.

- Local detachment of particle structures from a single filter fibre without reaction occurred at 1.9-2.6 m/s at ambient temperature. The detached fraction of the projection area is $0.05 \mathrm{~mm}^{2} / 16.92 \mathrm{~mm}^{2}$.

- Local detachment of particle structures from a single filter fibre with reaction occurred at $0.5 \mathrm{~m} / \mathrm{s}$ at $>400{ }^{\circ} \mathrm{C}$. The detached fraction of the projection area is $0.56 \mathrm{~mm}^{2} / 16.21 \mathrm{~mm}^{2}$.

- Experiments with nitrogen at temperatures between 100 and $500{ }^{\circ} \mathrm{C}$ showed no detachment phenomena at flow velocities below $3.0 \mathrm{~m} / \mathrm{s}$, which indicates that the detachment enhancement is not only caused by evaporation of water. These experiments show that higher temperatures even hinder particle detachment.

- Theoretical considerations about the influence of particle structure parameters on the breaking stress of the particle structure show, that the changes of the particle structure parameters may explain the different detachment velocities.

Further investigations using experiments and computational fluid dynamics are planned to quantify the influence of different parameters like the particle structure or the reactive-inert ratio on detachment.
Acknowledgements We gratefully acknowledge that this project was funded by the Deutsche Forschungsgemeinschaft (DFG, German Research Foundation)— 434784957.

Funding Open Access funding enabled and organized by Projekt DEAL.

\section{Compliance with ethical standards}

Conflict of interest The authors follow no commercial interests with this study. On behalf of all authors, the corresponding author states that there is no conflict of interest.

Open Access This article is licensed under a Creative Commons Attribution 4.0 International License, which permits use, sharing, adaptation, distribution and reproduction in any medium or format, as long as you give appropriate credit to the original author(s) and the source, provide a link to the Creative Commons licence, and indicate if changes were made. The images or other third party material in this article are included in the article's Creative Commons licence, unless indicated otherwise in a credit line to the material. If material is not included in the article's Creative Commons licence and your intended use is not permitted by statutory regulation or exceeds the permitted use, you will need to obtain permission directly from the copyright holder. To view a copy of this licence, visit http://creativecommons.org/licenses/by/4.0/.

\section{References}

Berbner S, Löffler F (1994) Influence of high temperatures on particle adhesion. Powder Technol 78:273-280

Dahneke B (1972) The influence of flattening on the adhesion of particles. J Colloid Interface Sci 40:1-13. https://doi. org/10.1016/0021-9797(72)90168-3

Götzinger M, Peukert W (2004) Particle adhesion force distributions on rough surfaces. Langmuir 20:5298-5303. https://doi.org/10.1021/ la049914f

Hamaker HC (1937) The London - van der Waals attraction between spherical particles. Physica 4:1058-1072. https://doi.org/10.1016/ S0031-8914(37)80203-7

Hurley JP, Dockter BA (2003) Factors affecting the tensile strength of hot-gas filter dust cakes. Adv Powder Technol 14:695-705

Jankowska E, Reponen T, Willeke K, Grinshpun SA, Choi K-J (2000) Collection of fungal spores on air filters and spore reentrainment from filters into air. J Aerosol Sci 31:969-978. https://doi. org/10.1016/S0021-8502(00)00017-3

Jiang K, Pinchuk P (2016) Temperature and size-dependent Hamaker constants for metal nanoparticles. Nanotechnology 27:1-9. https ://doi.org/10.1088/0957-4484/27/34/345710

Johnston AM, Vincent JH, Jones AD (1987) Electrical charge characteristics of dry aerosols produced by a number of laboratory mechanical dispensers. Aerosol Sci Technol 6:115-127. https:// doi.org/10.1080/02786828708959125

Kim SC, Wang J, Shin WG, Scheckman JH, Pui DYH (2009) Structural properties and filter loading characteristics of soot agglomerates. Aerosol Sci Technol 43:1033-1041. https://doi.org/10.1080/02786 820903131081

Lai T, Chen R, Huang P (2015) Temperature dependence of microscale adhesion force between solid surfaces using an AFM. J Adhes Sci Technol 29:133-148. https://doi.org/10.1080/01694 243.2014.977698 
Löffler F (1972) Abblasen von an Filterfasern abgeschiedenen Feststoffteilchen. Verfahrenstechnik 6:3-7

Maus R, Umhauer H (1996) Collection and adhesion efficiency of biological particles on single fibers. J Aerosol Sci 27:S255-S256. https://doi.org/10.1016/0021-8502(96)00200-5

Moore RH, Ziemba LD, Dutcher D, Beyersdorf AJ, Chan K, Crumeyrolle S, Raymond TM, Thornhill KL, Winstead EL, Anderson BE (2014) Mapping the operation of the miniature combustion aerosol standard (Mini-CAST) soot generator. Aerosol Sci Technol 48:467-479. https://doi.org/10.1080/02786826.2014.890694

Onischuk AA, Di Stasio S, Karasev VV, Baklanov AM, Makhov GA, Vlasenko AL, Sadykova AR, Shipovalov AV, Panfilov VN (2003) Evolution of structure and charge of soot aggregates during and after formation in a propane/air diffusion flame. J Aerosol Sci 34:383-403. https://doi.org/10.1016/S0021-8502(02)00215-X

Otsu N (1979) A Threshold Selection Method from Gray-Level Histograms. IEEE Trans. Syst. Man, Cybern 9:62-66. https://doi. org/10.1109/TSMC.1979.4310076
Przekop R, Grzybowski K, Gradoń L (2004) Energy-balanced oscillatory model for description of particles deposition and re-entrainment on fiber collector. Aerosol Sci Technol 38:330-337. https:// doi.org/10.1080/02786820490427669

Qian Y, Willeke K, Ulevicius V, Grinshpun SA (1997) Particle reentrainment from fibrous filters. Aerosol Sci Technol 27:394-404. https://doi.org/10.1080/02786829708965480

Rembor H-J, Maus R, Umhauer H (1999) Measurements of single fibre efficiencies at critical values of the stokes number. Part Part Syst Charact 16:54-59. https://doi.org/10.1002/(SICI)15214117(199906)16:2\%3c54:AID-PPSC54\%3e3.0.CO;2-P

Rumpf, (1970) Zur theorie der zugfestigkeit von agglomeraten bei kraftübertragung an kontaktpunkten. Chem Ing Tec 42:538-540

Schaefer DM, Carpenter M, Gady B, Reifenberger R, Demejo LP, Rimai DS (1995) Surface roughness and its influence on particle adhesion using atomic force techniques. J Adhes Sci Technol 9:1049-1062. https://doi.org/10.1163/156856195X00897 